\title{
Surgical Treatment of Adult Extra-Articular Distal Humeral Diaphyseal Fractures Using an Oblique Metaphyseal Locking Compression Plate via a Posterior Approach
}

\author{
Qing Yang Fang Wang Qiugen Wang Wei Gao Jianhua Huang Xiaofeng Wu \\ Jiaqi Wu Hao Chen
}

Department of Orthopedic Surgery, Shanghai First People's Hospital, Medical College, Shanghai Jiaotong

University, Shanghai, China

\author{
Key Words \\ Distal humeral fracture $\cdot$ Open reduction and internal \\ fixation - Fixation - Locking compression plates • \\ Osteosynthesis $\cdot$ Complication
}

\begin{abstract}
Objective: The purpose of this study was to evaluate the feasibility and clinical outcome of using an oblique AO (Association for the Study of Internal Fixation) metaphyseal locking compression plate (MLCP) in the treatment of adult extra-articular distal humeral diaphyseal fractures via a posterior approach. Subjects and Methods: A series of 19 cases of adult extra-articular distal humeral diaphyseal fractures were surgically treated using an MLCP and lag screws, if necessary, via a posterior approach. All patients were followed for a mean time of 16.6 months (range from 12 to 20 months). The patients were followed up to 1 year, and radiological assessment was performed to observe fracture reduction and healing. Functional outcome was measured including the range of motion of the shoulder and elbow, by the University of California at Los Angeles and the Mayo Elbow Performance Score. Results: The incidence of iatrogenic radial nerve palsy was $5 \%$. There was no failure of internal fixation
\end{abstract}

and no infection. After 1 year, the University of California at Los Angeles scoring system rated 12 (63.2\%) patients as excellent results. The Mayo elbow performance scoring system rated 10 (84\%) cases as excellent results. Completely normal alignment was presented in 16 cases. Conclusion: Following surgical treatment of adult extra-articular distal humeral diaphyseal fractures, an oblique MLCP applied via a posterior approach achieved an adequate internal fixation and obtained an excellent functional outcome.

Copyright $\odot 2011$ S. Karger AG, Basel

\section{Introduction}

Fractures of the adult extra-articular distal humeral diaphysis are relatively rare. For these fractures, surgical treatment provides a more predictable alignment and potentially quicker return of function [1-3]. However, the combination of the complex anatomy of the distal part of the humeral and complicated fracture morphology creates a challenge for the treating surgeon [4]. For the displaced fracture of the adult distal humeral diaphysis, the consensus is that stabilization of such fractures is appropriate $[3,5,6]$. Although there are numerous studies dis-

\section{KARGER}

Fax +4161306 1234

E-Mail karger@karger.ch

www.karger.com
(C) 2011 S. Karger AG, Basel

1011-7571/12/0211-0040\$38.00/0

Accessible online at:

www.karger.com/mpp
Prof. Qiugen Wang

Department of Orthopedic Surgery, Shanghai First People's Hospital

Medical College, Shanghai Jiaotong University

100 Haining Road, Shanghai 200080 (China)

Tel. +861380186 2558, E-Mail wangqiugen@126.com 
cussing the results of surgical fixation of displaced diaphyseal fractures of the adult humerus [7-11], few studies $[12,13]$ have specifically addressed the results using AO (Association for the Study of Internal Fixation) metaphyseal locking compression plates (MLCPs). The advantages of MLCPs include decreased surgical exposure and time, and potentially faster rehabilitation by minimizing the extent of the soft-tissue dissection. Therefore, we have conducted this retrospective study to determine the effects of open reduction and internal fixation of displaced fractures of the adult extra-articular distal humeral diaphysis using the AO MLCP.

\section{Subjects and Methods}

\section{Patients}

From July 2006 to August 2009, 19 extra-articular distal humeral diaphysis fractures in adults were surgically treated using the AO MLCP via a posterior approach. Patients with closed displaced unstable distal humeral diaphyseal fractures were included. Exclusion criteria were non-displaced fractures, severely comminuted fractures, fractures that extended to the joint and pathological fractures. There were 15 men and 4 women with a mean age of 36.7 years (range 20-75). All 19 cases were unilateral. The right humerus was involved in 13 and the left in 6 cases. There were 18 cases of isolated distal third humeral shaft fractures, and only 1 with ipsilateral femoral shaft fractures. All fractures were closed injuries. The locations and patterns of the fractures as determined by the AO/Orthopaedic Trauma Association classification [14] are listed in table 1. All 19 patients were available for follow-up examination.

\section{Surgical Technique}

The operations were performed by a single surgeon (Q.W.) under general anaesthesia and were performed for the range of 3-7 days after injury. The patient was placed in the prone position on the operating table with the arm abducted $90^{\circ}$ according to AO principles. A longitudinal incision was made in the midline of the posterior aspect of the arm, from $8 \mathrm{~cm}$ below the acromion to the olecranon fossa. The deep fascia of the arm was incised in line with the skin incision. Proximally, the radial nerve and profunda brachii vessels were exposed by retracting the lateral head of the triceps laterally and the long head of the triceps medially. Distally, the triceps aponeurosis was split down the middle, and the medial head was then split in line with its fibres to expose the humerus. Further dissection of the soft tissue was limited on the posterior surface to preserve the blood supply of the humerus.

Manipulative reduction was performed under direct visualization. K wires and lag screws were used for temporary stabilization to correct the displacement of the fractures and restore the axis of the humerus. Intra-operative imaging with a $\mathrm{C}$ arm was used to confirm the adequacy of the reduction. The AO MLCP was placed along the posterior surface of the lateral column. The proximal end of the plate was placed beneath the radial nerve and profunda brachii vessels, and positioned on the posterior surface of the humerus. The distal end of the plate was positioned to avoid en-
Table 1. Data after initial trauma

\begin{tabular}{|c|c|c|c|c|c|c|}
\hline $\begin{array}{l}\text { Pat. } \\
\text { No. }\end{array}$ & Sex & $\begin{array}{l}\text { Age, } \\
\text { years }\end{array}$ & $\begin{array}{l}\text { Mechanism } \\
\text { of injury }\end{array}$ & $\begin{array}{l}\text { Involved } \\
\text { side }\end{array}$ & $\begin{array}{l}\text { AO/OTA } \\
\text { classification }\end{array}$ & $\begin{array}{l}\text { Associated } \\
\text { injuries }\end{array}$ \\
\hline 1 & $\mathrm{M}$ & 75 & MVA & right & $12 \mathrm{~A} 2.3$ & none \\
\hline 2 & $\mathrm{M}$ & 27 & MVA & right & $12 \mathrm{C} 1.3$ & none \\
\hline 3 & $\mathrm{M}$ & 29 & fall & right & $12 \mathrm{~B} 1.3$ & none \\
\hline 4 & $\mathrm{M}$ & 49 & fall & right & $12 \mathrm{~B} 1.3$ & none \\
\hline 5 & $\mathrm{M}$ & 22 & MVA & left & $12 \mathrm{~B} 2.3$ & none \\
\hline 6 & $\mathrm{M}$ & 26 & MVA & left & $12 \mathrm{~A} 2.3$ & none \\
\hline 7 & $\mathrm{M}$ & 40 & MVA & left & $12 \mathrm{~B} 2.3$ & none \\
\hline 8 & $\mathrm{M}$ & 42 & MVA & right & $12 \mathrm{C} 1.1$ & none \\
\hline 9 & $\mathrm{~F}$ & 28 & MVA & right & $12 \mathrm{~A} 3.3$ & none \\
\hline 10 & $\mathrm{M}$ & 35 & MVA & left & $12 \mathrm{~B} 2.3$ & none \\
\hline 11 & $\mathrm{M}$ & 34 & $\mathrm{RM}$ & right & $12 \mathrm{~B} 1.3$ & none \\
\hline 12 & $\mathrm{M}$ & 61 & MVA & right & $12 \mathrm{~A} 2.3$ & none \\
\hline 13 & $\mathrm{M}$ & 26 & fall & right & $12 \mathrm{~A} 1.3$ & none \\
\hline 14 & $\mathrm{~F}$ & 30 & MVA & left & $12 \mathrm{~A} 2.3$ & none \\
\hline 15 & $\mathrm{~F}$ & 49 & MVA & left & $12 \mathrm{~B} 3.3$ & none \\
\hline 16 & $\mathrm{~F}$ & 44 & MVA & right & $12 \mathrm{~A} 2.3$ & none \\
\hline 17 & $\mathrm{M}$ & 20 & MVA & right & $12 \mathrm{~A} 2.3$ & $\begin{array}{l}\text { right femoral } \\
\text { shaft fracture }\end{array}$ \\
\hline 18 & $\mathrm{M}$ & 26 & fall & right & $12 \mathrm{~B} 1.3$ & none \\
\hline 19 & $\mathrm{M}$ & 34 & MVA & right & $12 \mathrm{~A} 2.3$ & none \\
\hline
\end{tabular}

Pat. = Patient; OTA $=$ Orthopaedic Trauma Association; $\mathrm{M}=$ male; $\mathrm{F}=$ female MVA $=$ motor vehicle accident $\mathrm{RM}=$ rolled in machine.

Fig. 1. The radial nerve and profunda brachii artery with 2 accompanying veins were identified by retracting the lateral head of triceps laterally. Anatomic reduction was achieved by an AO MLCP and lag screws.

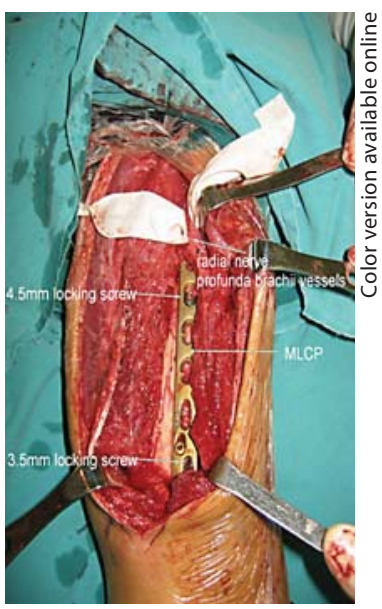

croachment upon the olecranon fossa (fig. 1). At least 3 screws were placed on either side of the fracture site. When possible, 4 screws were placed in the distal part of the plate to enhance the antipullout force [15]. The $\mathrm{K}$ wires were then removed; the apposition and alignment of the fragments were then checked again with the $\mathrm{C}$ arm, and significant valgus or varus deviation, if any, were reset. When anatomical alignment was achieved, the locking screws were then locked, the radial nerve was released, the incision irri- 
Table 2. Results of adult patients with distal humerus diaphyseal fractures

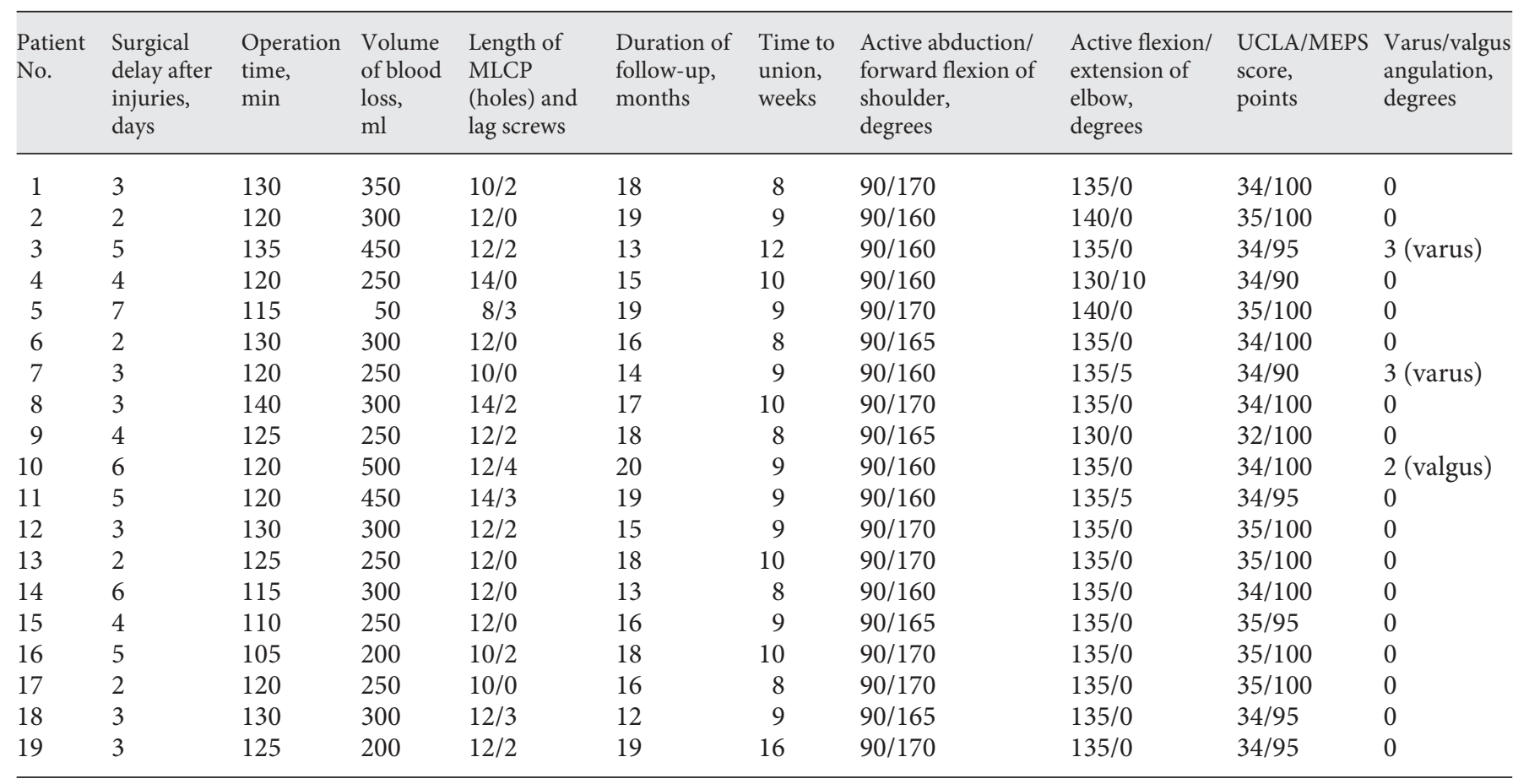

UCLA = University of California at Los Angeles; MEPS = Mayo Elbow Performance Score.

gated, and if necessary, a drainage tube was attached. Care was taken not to injure important structures when closing the incision.

\section{Postoperative Care}

All patients were followed up for a mean time of 16.6 months (range from 12 to 20). Postoperatively, the arm was immobilized with a neck-wrist sling for 4-6 weeks, and active shoulder and elbow exercises were encouraged early, usually $3-5$ days after surgery. The drainage tube was removed at $24 \mathrm{~h}$, and the incision was observed carefully. Furthermore, antibiotics were used for 3-5 days for all patients in case of postoperative infection.

For data collection, the operative time was defined as the time from the skin incision to skin closure. Also recorded was the fracture healing time, perioperative and later complications, shoulder and elbow functions. The data regarding shoulder and elbow functions were collected and assessed by one surgeon (J.H.) who was not associated with the surgical procedure or the care of the patients. All the patients were followed postoperatively with clinical and radiographic examinations at 4 -week intervals, and more active exercises were started when callus appeared. Union was defined as the absence of pain and the presence of bridging calluses in 3 of the 4 cortices seen on the anteroposterior and lateral radiographic views of the humerus. Alignment was assessed on the final anteroposterior and lateral radiographs of the humerus. Shoulder function was assessed using the University of California at Los Angeles scoring system [16], while the elbow function was assessed using the Mayo Elbow Performance Score [17].

\section{Results}

The individual surgical data are listed in table 2. The mean operation time was $122.9 \pm 8.5 \mathrm{~min}$ (range $105-$ 140 ); the mean intra-operative blood loss was $289.5 \pm$ $100.8 \mathrm{ml}$ (range 50-500); all the fractures healed with a mean healing time of $9.5 \pm 1.9$ weeks (range $8-16$ ). There was only 1 iatrogenic radial nerve palsy (patient 2), in a case which recovered completely within 2.5 months after the operation. All cases were sufficiently stabilized using a single MLCP. There was no failure of internal fixation and also no superficial or deep infection. Implants were removed from 2 patients (cases 4 and 7 ) who complained of pressure on the overlying skin, or by patient request. After removal of the hardware, further rehabilitation was subsequently performed and patients showed good functional outcome. The mean active forward flexion of the shoulder was $165.3 \pm 4.6^{\circ}$ (range 160-170). The University of California at Los Angeles scoring system rated $12(63.2 \%)$ patients as showing excellent results and 7 $(36.8 \%)$ as showing good recovery. The mean active forward flexion of the elbow was $135.0 \pm 2.4^{\circ}(130-140)$. The Mayo elbow performance scoring system rated 10 
Fig. 2. Pre-operative anteroposterior radiograph of the right humerus in a 27-yearold male showed a spiral fracture $(\mathrm{AO} /$ Orthopaedic Trauma Association 12C1.3) of the distal humeral diaphysis with displacement of the distal fragment.

Fig. 3. Postoperative anteroposterior radiograph of the right humerus with an $\mathrm{AO}$ 3.5-mm and 4.5-mm MLCP and 4 cortical screws after 12 months showed bony union in an anatomical alignment.

Fig. 4. Postoperative lateral radiograph of the right humerus after 12 months showed bony union in an anatomical alignment.
2

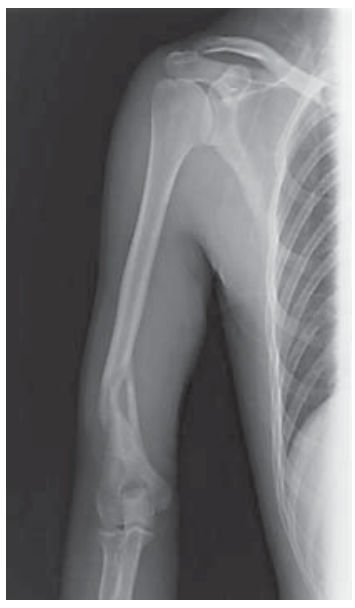

3

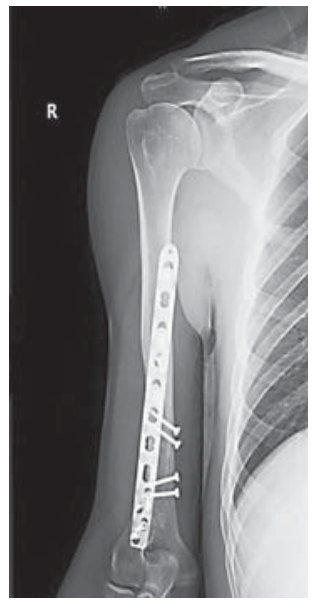

4

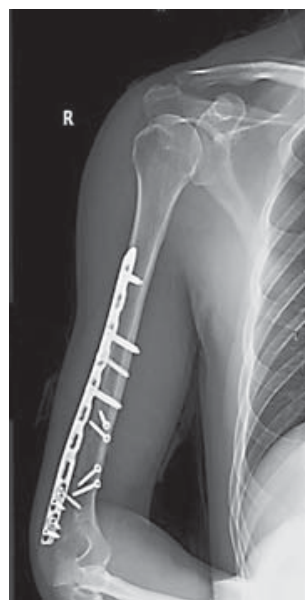

5

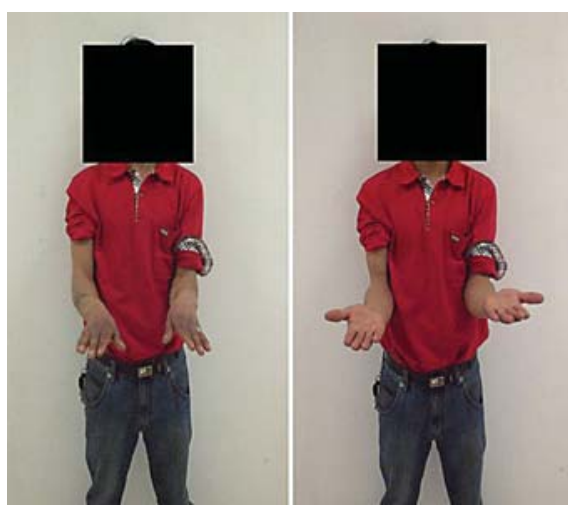

6

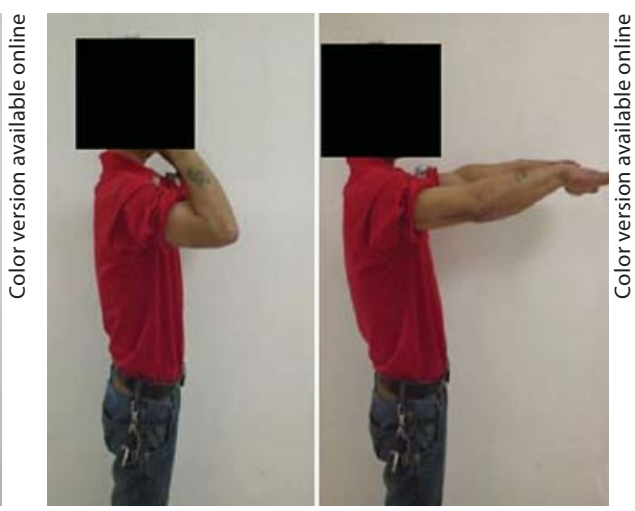

Fig. 5. Functional outcome after 12 months showing a good range of motion in pronation and supination.

Fig. 6. Functional outcome after 12 months showing a good range of motion in flexion and extension.

(52.6\%) cases as excellent results, $6(31.6 \%)$ as good and 3 (15.8\%) as fair.

At their final follow-up, all 19 patients had an anteroposterior and lateral radiograph of the humerus taken to measure humeral axial alignment that showed completely normal alignment in $16(84.4 \%)$ cases, while varus deformities of $3^{\circ}$ were found in $2(10.5 \%)$ cases; $2^{\circ}$ was noticed in only $1(5.3 \%)$ case (table 2$)$. Typical cases of postoperative anteroposterior radiographs are shown in figures 2-4. The final functional outcome after the last follow-up (fig. 5,6 ) showed a good range of motion in flexion and extension, as well as pronation and supination.

\section{Discussion}

Our clinical study using this technique was useful in reducing the incidence of complications, obtaining a fully good functional outcome in the shoulder of all the patients and in a majority in the elbow. The $10.5 \%$ rate of tenderness after internal fixation of our study was lower than the $38.8 \%$ reported by Celli et al. [18]. The 105-140 min range of operation time in our study was shorter than the 150-215 min in the studies by Soon et al. [19] and Reising et al. [20]. Although meticulous radial nerve protection is emphasized in plate fixation, the 5.3\% incidence of iatrogenic radial nerve palsies was slightly lower than the $10.1 \%$ reported by Vazquez et al. [21]. A probable explanation of our findings and other studies $[18,21]$ could be due to the extensive soft-tissue stripping that is involved in the dual-plating technique, thereby resulting in a longer operation time and a high rate of tenderness. Equally important, other studies $[9,11]$ using the single-plating technique for diaphyseal humeral fractures have reported good clinical outcome.

With the previous single-plating techniques, adequate stabilization of distal fractures of the humeral diaphysis was usually difficult to achieve and was compli- 
cated by extension into the metaphyseal region. The distal fragments are frequently small and have a limited amount of subchondral bone. Moreover, the bone is osteoporotic especially in elderly patients. This could lead to a decreased screw-holding strength in the distal fragments. Also, the elbow joint has a tendency to react with contracture and loss of active range of motion to every trauma, surgery or immobilization and, therefore, requires stable internal fixation to allow for early rehabilitation.

In our study, the use of this method of reduction and fixation defined by the various surgical steps may also be useful for improving fracture reduction and stabilization in the adequate biomechanically advantageous manner. The advantage of the MLCP described in this series is the distal cluster of smaller-diameter screws, which allows the plate to be applied proximal to the olecranon fossa, thereby minimizing distal soft-tissue dissection and potential nerve compromise. Adequate stabilization of the distal part of the fragment relies on the special design of the locking plate, such as small-caliber screws and overlapping holes. Lag screws are applied to help achieve anatomical reduction and stabilize the fractured bony segments when necessary.

We believe the use of MLCP with an oblique arrangement to be of substantial aid in obtaining anatomical reduction, thus making it possible to control the correct recovery of both the diaphyseal axis and the distal humeral axis. Posterior fixation of the lateral column, using the overlapping 3.5-mm locking screws, makes it possible to obtain significant distal humeral stability. The distal screw overlap concept proposed in this fixation solution aims to reinforce and support the distal fragment of the humerus discharging the stress forces on the plate onto the column. Oblique plate arrangement makes it possible to increase stability in the meta-epiphyseal area, which is at risk at non-union using an unstable fixation. A significant sensation of fracture stability is achieved during surgery with just 1 MLCP and lag screws, if possible, such as to allow flexion-extension motion without affecting the elbow. With the MLCP, the distal fractures of the humeral diaphysis can be rigidly fixed without compromising the elbow. This is a novel method of fixing these difficult fractures, and our data show excellent restoration and maintenance of reduction and alignment with very few complications.

\section{Limitations of the Study}

The major limitations of our study are the small number of patients and the lack of a control group for comparison.

\section{Conclusion}

The oblique plating technique was a useful treatment option in the management of distal fractures of the humeral diaphysis. The adequate stability of the system, allowing early range of motion, was probably the most important advantage of this technique. Introduction of an early rehabilitation programme along with the emphasis on the early use of the elbow could improve the functional success of this technique.

\section{References}

1 Riemer B: Distal diaphyseal fracture of the humerus. Techn Orthopaed 2003;18:360367.

2 Niall DM, O’Mahony J, McElwain JP: Plating of humeral shaft fractures - has the pendulum swung back? Injury 2004;35:580-586.

-3 Jawa A, McCarty P, Doornberg J, Harris M, Ring D: Extra-articular distal-third diaphyseal fractures of the humerus. A comparison of functional bracing and plate fixation. J Bone Joint Surg Am 2006;88:2343-2347.

4 Jupiter JB, Morrey BF: Fractures of the distal humerus in adults; in Lampert R (ed): The Elbow and Its Disorder, ed 3. Philadelphia, Saunders Co, 2000, pp 293-329.
5 Sarmiento A, Waddell JP, Latta LL: Diaphyseal humeral fractures: treatment options. J Bone Joint Surg Am 2006;88:1625-1628.

6 Jawa A: Treatment of distal diaphyseal humerus fractures. J Hand Surg Am 2010;35: 301-302.

7 Brug E, Winckler S, Klein W: Distal diaphyseal fracture of the humerus. Unfallchirurg 1994;97:74-77.

8 Moran MC: Modified lateral approach to the distal humerus for internal fixation. Clin Orthop 1997;190-197.

> Levy JC, Kalandiak SP, Hutson JJ, Zych G: An alternative method of osteosynthesis for distal humeral shaft fractures. J OrthopTrauma 2005;19:43-47.
10 Livani B, Belangero WD, Castro MR: Fractures of the distal third of the humerus with palsy of the radial nerve: management using minimally invasive percutaneous plate osteosynthesis. J Bone Joint Surg Br 2006;88: $1625-1628$.

11 Zhiquan A, Bingfang Z, Yeming W, Chi Z, Peiyan $\mathrm{H}$ : Minimally invasive plating osteosynthesis (MIPO) of middle and distal third humeral shaft fractures. J Orthop Trauma 2007;21:628-633.

12 Spitzer AB, Davidovitch RI, Egol KA: Use of a 'hybrid' locking plate for complex metaphyseal fractures and nonunions about the humerus. Injury 2009;40:240-244. 
13 Gupta RK, Rohilla RK, Sangwan K, Singh V, Walia S: Locking plate fixation in distal metaphyseal tibial fractures: series of 79 patients. Int Orthop 2010;34:1285-1290.

- 14 Marsh JL, Slongo TF, Agel J, Broderick JS, Creevey W, DeCoster TA, Prokuski L, Sirkin MS, Ziran B, Henley B, Audigé L: Fracture and dislocation classification compendium. J Orthop Trauma 2007;21(suppl):S1-S133.

15 Stoffel K, Dieter U, Stachowiak G, Gächter A, Kuster MS: Biomechanical testing of the LCP - how can stability in locked internal fixators be controlled? Injury 2003;34(suppl 2):11-19.
6 Ellman H, Hanker G, Bayer M: Repair of the rotator cuff. J Bone Joint Surg Am 1986;68: 1136-1144.

17 Gill DR, Morrey BF: The Coonrad-Morrey total elbow arthroplasty in patients who have rheumatoid arthritis. A ten to fifteen-year follow-up study. J Bone Joint Surg Am 1998; 80:1327-1335.

18 Celli A, Donini MT, Minervini C: The use of pre-contoured plates in the treatment of $\mathrm{C}_{2}-$ $\mathrm{C}_{3}$ fractures of the distal humerus: clinical experience. Chir Organi Mov 2008;91:5764.
Soon JL, Chan BK, Low CO: Surgical fixation of intra-articular fractures of the distal humerus in adults. Injury 2004;35:44-54.

20 Reising K, Hauschild O, Strohm PC, Suedkamp NP: Stabilisation of articular fractures of the distal humerus: early experience with a novel perpendicular plate system. Injury 2009;40:611-617.

21 Vazquez O, Rutgers M, Ring DC, Walsh M, Egol KA: Fate of the ulnar nerve after operative fixation of distal humerus fractures. J Orthop Trauma 2010;24:395-399. 